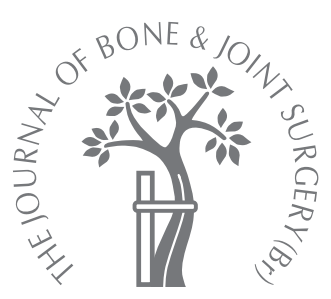

L. Kerboull, M. Hamadouche, M. Kerboull

From the Marcel Kerboull Institute, Paris, France

\title{
Impaction grafting in association with the Charnley-Kerboull cemented femoral component
}

\author{
OPERATIVE TECHNIQUE AND TWO- TO 16-YEAR FOLLOW-UP \\ RESULTS
}

\begin{abstract}
We describe 129 consecutive revision total hip replacements using a Charnley-Kerboull femoral component of standard length with impaction allografting. The mean follow-up was 8.2 years (2 to 16). Additionally, extramedullary reinforcement was performed using struts of cortical allograft in $\mathbf{4 9}$ hips and cerclage wires in 30.

There was one intra-operative fracture of the femur but none later. Two femoral components subsided by $5 \mathrm{~mm}$ and $8 \mathrm{~mm}$ respectively, and were considered to be radiological failures. No further revision of a femoral component was required. The rate of survival of the femoral component at nine years, using radiological failure as the endpoint, was $98 \%$. Our study showed that impaction grafting in association with a Charnley-Kerboull femoral component has a low rate of subsidence. Reconstruction of deficiencies of distal bone with struts of cortical allograft appeared to be an efficient way of preventing postoperative femoral fracture for up to 16 years.
\end{abstract}

The treatment of extensive femoral bony defects related to loosening of an implant after total hip replacement (THR) is still a matter of debate. The use of a larger and/or longer cemented implant has been shown to be ineffective with a survivorship of $75 \%$ at eight years according to Stromberg, Herberts and Palmertz. ${ }^{1}$ Currently, two main surgical options are used. The first involves the implantation of a long, uncemented femoral component to obtain distal fixation and regeneration of proximal bone. ${ }^{2,3}$ The second involves massive or morcellised allograft bone in association with a cemented femoral component. Difficulties related to the availability of massive allografts have restricted their case so that they are now limited to major femoral cortical deficiencies. ${ }^{4}$ By contrast, since its first description by Simon et $\mathrm{al}^{5}$ in 1991, the favourable results of femoral impaction grafting have made this an accepted technique. ${ }^{6-9}$ However, the high prevalence of peri-operative femoral fractures and post-operative subsidence of the femoral component remains a cause for concern. ${ }^{10-14}$ Our experience with femoral impaction grafting began in 1989. From 1991, we have been using specialised instrumentation specifically designed for impaction grafting with a standard length of Charnley-Kerboull femoral component (Kerboull MKIII, Stryker Howmedica, Herouville Saint Clair, France and Original Concept, Biomet, Valance,
France). In addition, any thinning or defects in the femur were reinforced with extramedullary struts of cortical allograft or wires before the intramedullary reconstruction. We considered that these technical modifications in association with a femoral component which was not designed to subside within the cement mantle, would decrease the prevalence of perioperative fractures and migration of the femoral component.

We have retrospectively reviewed our experience of femoral impaction grafting in 129 hips, with special emphasis on peri-operative complications and subsidence of the femoral component after a minimum of two years.

\section{Patients and Methods}

From a computer database, we identified 129 patients (70 women and 59 men) who had undergone femoral impaction grafting by one surgeon (LK) during revision THR between January 1991 and December 2005. Their mean age at the time of revision was 64 years (43 to 79). The indication for revision of the femoral component was aseptic loosening in 127 hips and a one-stage procedure for the treatment of infection in the remaining two. The revised femoral component was cemented in 119 hips and uncemented in ten. The mean number of revisions before the initial procedure was 1.33 ( 1 to 3). The procedure was the first femoral revision in 96 hips, the second in 23 and the third in ten. 
Pre-operative bone loss was graded according to the EndoKlinik system ${ }^{15}$ using anteroposterior (AP) radiographs of the pelvis, and AP and lateral views of the affected hip and femur. In addition, patients operated on after January 2000 had CT of the hip including the proximal and distal parts of the femoral diaphysis. Of the 129 hips, 75 were classified as grade 1,43 as grade 3 , and 11 as grade 4 .

Implants and pre-operative planning. The femoral component was introduced at our institute in 1972. It is made of 316L stainless steel with a highly-polished surface finish ( $\mathrm{Ra}$ $=0.04 \mu \mathrm{m}$ ) and a quadrangular section. Pre-operative planning was performed to determine if the femoral component would restore neck length with respect to the desired length of the operated limb, restore the offset, and have an intramedullary size which would allow substantial grafting. In hips with deficiencies of the medial metaphysis and femoral neck, dysplastic straight femoral components were used since they have the same neck length as standard components but a thinner body, thereby allowing a larger reconstruction. Using a template of the predicted component, the area located between the tip of the prosthesis and the distal femoral cortices not affected by osteolysis, was assessed in order to decide whether there was need for reinforcement of this area using intra- or extramedullary grafting to bypass the tip of the prosthesis. In addition, areas with cortical weakness in the proximal part of the femur were systematically reconstructed with allograft cortical struts or reinforced with wires to avoid fracture during impaction.

Intra-operative data. The operative technique has been described in detail. ${ }^{28}$ A lateral approach with a standard trochanteric osteotomy was used in all hips. The joint capsule and any scar tissue around the proximal femur were completely excised. The hip was gently dislocated to avoid damaging the weak proximal femur. Removal of the components, debris and cement was carefully performed with complete resection of fibrous tissue within the medullary canal. In 125 hips all residual distal bone cement, including the plug, was removed using chisels, curettes and drills. In the remaining four, a cortical femoral window was made in order to allow extraction of a distally wellfixed uncemented femoral component with associated proximal osteolysis. Before impaction grafting, femoral segmental bone defects, or windows, were reconstructed and reinforced with struts of cortical allograft and/or cerclage wires. The calcar and medial femoral cortex were reinforced with strut grafts and cerclage wires in 15 hips and the lateral cortex in 16. In 18 hips a distal femoral segmental defect was augmented with a cortical strut which bypassed the tip of the femoral component. Of these 18 hips, seven required circumferential augmentation with struts. In another 30 hips, isolated cerclage wires were used to support the weakened bone in order to prevent fracture during impaction. Extramedullary reinforcement was associated with the impaction grafting, including allograft struts and/or cerclage wires in 76 of the 129 hips $(58.9 \%)$. Fresh-frozen femoral heads were

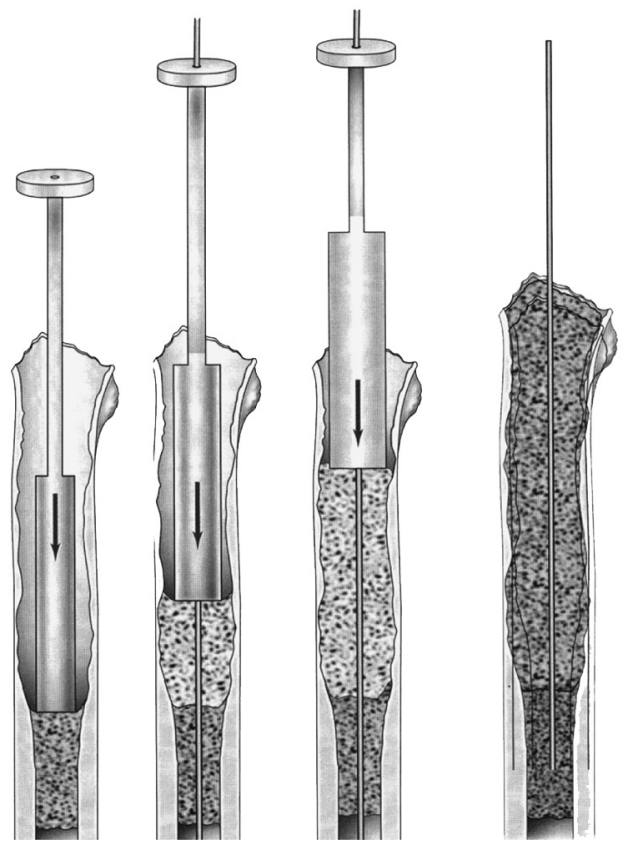

Fig. 1

Diagrams showing how the distal femoral canal is plugged with cancellous bone chips which are impacted using cylindrical impactors of increasing size.

obtained from a regional bone bank. The articular cartilage was removed and the heads sliced and milled by a Novio Magus bone mill (Spierings Medische Techniek, Nijmegen, The Netherlands) which produces bone chips with a diameter of between $5 \mathrm{~mm}$ and $8 \mathrm{~mm}$.

Specifically-designed revision instruments (Biomet) were used, including a guide-wire and cannuated distal and proximal phantom impactors assembled on a removable handle. The proximal impactors had the same shape as the final femoral component. The first step was to place a distal intramedullary bone plug approximately $2 \mathrm{~cm}$ below the tip of the component (Fig. 1). In hips with cortical deficiency or weakness below the tip of the component, intramedullary grafting was extended throughout the length of the weak area. A guide-wire was screwed into the distal plug before impaction. After the femoral canal had been washed, bone chips were inserted using the distal impactors. After completing the distal impaction, proximal impaction was performed with appropriately-sized phantoms passed over the guide-wire (Fig. 2). Block impactors were used to impact the graft tightly around the final phantom, which corresponded to the size of the final prosthesis. Moreover, in 58 hips, shaped cancellous bone blocks of allograft were inserted between the phantom and the posterior, anterior and medial cortices in order to increase rotational stability and avoid varus tilt of the femoral component. Palamed bone cement with gentamicin (Biomet) was then injected retrogradely into the neomedullary canal using a cement syringe before the femoral component was finally inserted. 


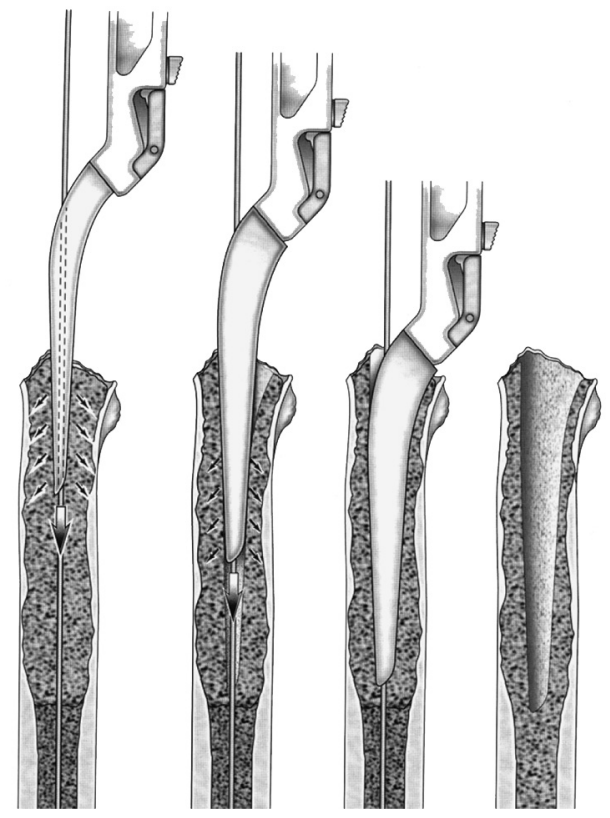

Fig. 2

Diagrams showing how vigorous proximal impaction is performed using phantoms of the prosthesis of increasing size.

Post-operative rehabilitation. The post-operative regimen included the administration of systemic antibiotics for 48 hours, thromboprophylaxis with enoxaparin $(40 \mathrm{mg} / \mathrm{day})$ until full weight-bearing was allowed, and antiinflammatory medication (ketoprofen, $100 \mathrm{mg} / \mathrm{day}$ ) to prevent heterotopic ossification. Immediately after the operation, passive exercises were begun with the assistance of a physiotherapist, and were continued until active movement of the hip was possible. The patients were free to walk after three days with crutches. Toe-touch weight-bearing was recommended for two months followed by a gradual increase to full weight-bearing, usually by the end of the third month after operation.

Clinical and radiological evaluation. This was undertaken at six weeks, three and six months and at one year. Patients were then reviewed every year for the first five years after operation and every two years thereafter. The functional results were rated according to the Merle d'Aubigné grading system ${ }^{17}$ in which an excellent result scored 18 points, a very good result 17 points, good 16 points, fair 15 points, poor 14 points and a bad result $\leq 13$ points. Radiological analysis was performed on serial AP radiographs of the pelvis and lateral radiographs of the femur. The parameters investigated included the presence of radiolucent lines in any of the zones described by Gruen, McNeice and Amstutz ${ }^{18}$ for the femur, and the alignment and subsidence of the stem. Subsidence was evaluated according to the method described by Fowler et al, ${ }^{19}$ based on the measurement of the vertical dimension of any radiolucency craniolateral to the shoulder of the femoral component in zone 1.
Radiological incorporation and the formation of trabecular bone in the graft were assessed using the criteria of Fowler et $\mathrm{al},{ }^{19}$ and heterotopic ossification according to the classification of Brooker et al. ${ }^{20}$ Loosening of the femoral component was defined according to the criteria of Harris and $\mathrm{McGann}^{21}$ including subsidence $\geq 3 \mathrm{~mm}$, fracture of the cement mantle (definite), a complete radiolucent line $\geq 2 \mathrm{~mm}$ (probable), or a radiolucent line in zone 1 equal $\geq 2 \mathrm{~mm}$ (potential). Definite, probable and potential evidence of loosening were considered in our study. ${ }^{21}$

Survivorship analysis. Survivorship analysis according to an actuarial method ${ }^{22,23}$ was carried out on the entire series using revision of the femoral component for any reason, and radiological loosening of the component at the time of follow-up, as endpoints. The survival curve was derived from the cumulative survival rate as calculated from the actuarial life table. ${ }^{22}$ The SEM, given as a percentage, and the $95 \%$ confidence interval (CI), were calculated from the data in the life table. ${ }^{23}$

\section{Results}

By the final follow-up examination, seven patients had died and two had been lost to follow-up. These nine patients had been assessed from two to ten years. We reviewed 120 patients clinically and radiologically after a mean follow-up of 8.2 years ( 2 to 16 ). There were 85 patients with a followup of more than five years.

Complications and revisions. These included one proximal intra-operative fracture of the femur which was immediately identified and treated with cerclage wires. The fracture healed with no further complication. One nonunion of the greater trochanter required re-operation and one patient had a dislocation two weeks after surgery. After reduction, there was no further recurrence. There was no closed subseqent femoral fracture. Heterotopic ossification was seen in three hips and was classified as grade 2 . No infection was recorded. One patient had a revision on the acetabular side at 11 years for loosening related to high polyethylene wear $(6 \mathrm{~mm})$. No patient was revised for loosening or subsidence of the femoral component.

Clinical. By the final follow-up examination, the clinical results were rated as excellent in 87 hips $(67.4 \%)$, very good or good in $40(31.0 \%)$ and fair in two $(1.6 \%)$. The mean functional Merle d'Aubigné hip score improved from 10.6 ( 8 to 12 ) pre-operatively to 16.6 (14 to 18 ) by the final follow-up. Of the 129 patients, two had a slight limp and used a stick to walk long distances. Leg-length discrepancy was corrected in 115 hips; lengthening of less than $1 \mathrm{~cm}$ was seen in 14 hips.

Radiological. On the first post-operative AP radiograph, the femoral component was in a neutral position in $95(73.6 \%)$ while 29 components $(22.5 \%)$ were in less than $4^{\circ}$ of valgus and five $(3.9 \%)$ in less than $4^{\circ}$ of varus. By the final review, one hip had subsided $5 \mathrm{~mm}$, with lucent lines at the graft-host interface in three Gruen zones. ${ }^{30}$ Another had subsided $8 \mathrm{~mm}$ within the cement 


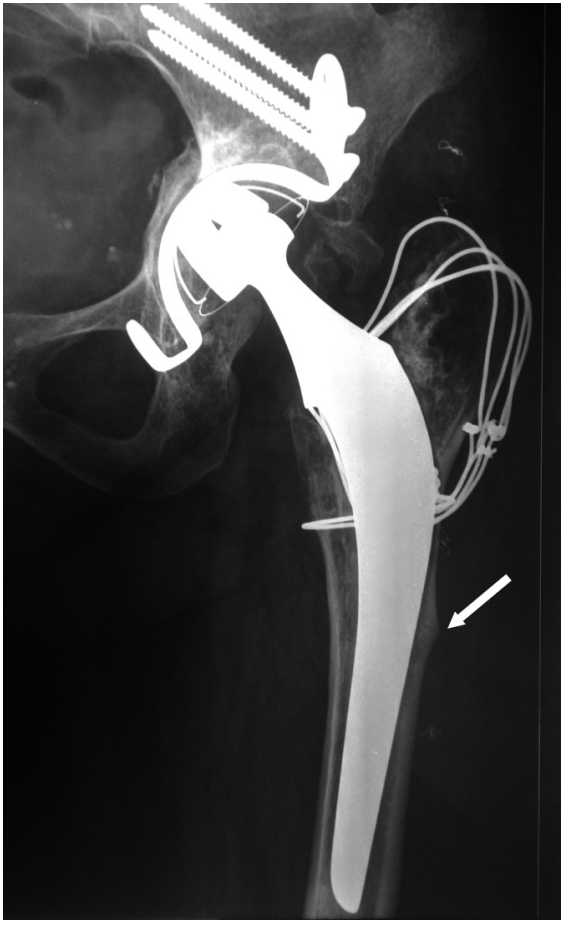

Fig. 3a

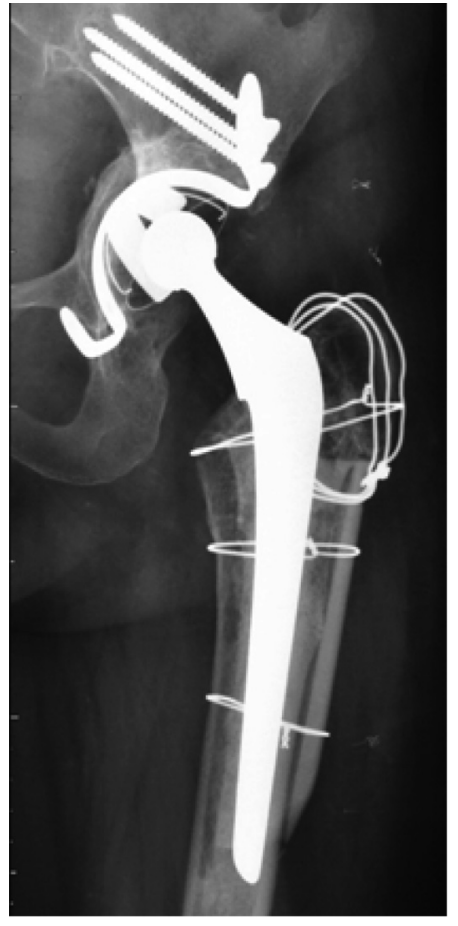

Fig. $3 b$

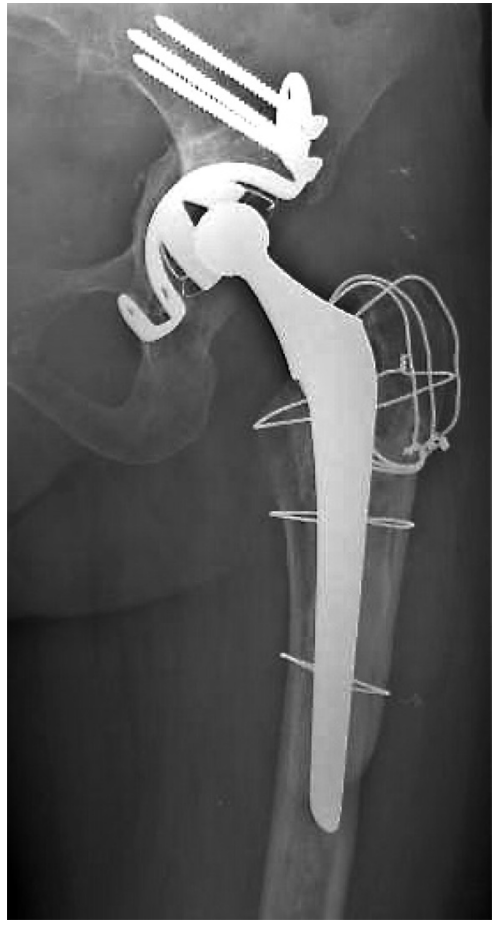

Fig. 3c

Figure 3a-Radiograph showing loosening at follow-up at ten years of a first revision which had been performed without bone reconstruction. There is distal migration of the femoral component associated with a fatigue fracture of the lateral cortex (arrow). Figure $3 \mathrm{~b}-$ Post-operative radiograph of the revision which was performed using femoral impaction grafting and a dysplastic stem, allowing a substantial intramedullary reconstruction, while also permitting the same length of neck as the previous component. The lateral and posterolateral cortices were reconstructed with allograft cortical struts. Figure $3 c$ - Radiograph at a follow-up at 12 years showing incorporation and remodelling of both the cortical struts and intramedullary allograft.

mantle, with a lucent line at the distal graft-host interface and a distal fracture of the cement mantle. These two hips with subsidence showed these changes in the first year after operation and then stabilised for up to four and nine years after surgery, respectively. Both had severe bone loss (Endo-Klinik grade 4) with a very large, cylindrical femur. One had an initial varus alignment of the component of $4^{\circ}$, and in both the quality of the impaction was poor. These two components were considered to be definitely loose, but neither was revised. The remaining 127 hips showed no radiological changes at the final examination in respect of migration of the femoral component or radiolucent lines. Cortical healing and thickening occurred in all zones in which cortical compromise had been present at the time of impaction grafting. All the allograft struts appeared to be incorporated and no demarcation between the host cortex and the graft was seen after the first 15 months (Fig. 3). Radiological trabecular remodelling and incorporation were observed in all hips, but it was not possible to quantify these processes.

Survivorship analysis. With revision for any reason as the endpoint, the cumulative survival rate at nine years was $100 \%$ for the femoral component. With radiological loosening as the endpoint, the cumulative survival rate at nine years was $98.0 \%$ (sd 4.9) (95\% CI 96.2 to 100$)$.

\section{Discussion}

The results of femoral impaction grafting in our series at a mean follow-up of 8.2 years in respect of the need for a further revision for any reason agree with the excellent outcomes reported by other authors. ${ }^{7-9,13-15,24-26}$ Radiological analysis of remodelling in the areas of compromised also confirmed the ability of this type of graft to be progressively transformed into viable and mechanically efficient new bone, as previously shown by Linder. ${ }^{27}$ However, the low rate of subsidence of the femoral component and the absence of post-operative femoral fracture differ from other studies. $^{8}$

The extent and patterns of subsidence depend on several factors, including the geometry of the femoral component, the operative technique and the mechanical resistance of the graft. Subsidence of the component may occur within the cement mantle or at the cement-graft interface. As demonstrated by Brewster et $\mathrm{al},{ }^{28}$ the graft behaves as a friable aggregate, and its resistance to load depends upon its nature, the impaction, and the type of stress applied. The experimental work of Giesen et $\mathrm{al}^{29}$ has shown that, in vivo, the graft is subjected to permanent deformation after loading. These authors suggested that the design of the implant should accommodate such visco-elastic graft deformation without causing loosening at the interface. Their 
studies suggest that subsidence of the femoral component depends mainly on the stability of the cement-graft interface since in vitro studies have shown that the cement mantle is supported by the graft and the most important factor which influences subsidence is the quality of impaction..$^{30,31}$ This determines the primary stability and the radiological incorporation of the graft to the host bone which is necessary to obtain secondary stability. The nature, treatment and size of the bone chips have also been evaluated, ${ }^{32-34}$ but these factors are, in our view, of minor importance when compared with the quality of impaction. One measured issue is whether subsidence of the femoral component within the cement mantle benefits the overall stability of the prosthesis-cement-graft-bone composite. The Exeter group has indicated that subsidence within the cement mantle is a normal and positive event in primary THR. ${ }^{19,35}$ Roentgen stereophotogrammetric analysis studies have demonstrated that subsidence is linked to the specific design of the Exeter femoral component, and occurs in the first three months after operation, mainly at the cement-stem interface. ${ }^{36-39}$ Although limited subsidence has been associated with good long-term results for the primary Exeter THR, ${ }^{40,41}$ the benefits of large degrees of subsidence $(>5 \mathrm{~mm}$ ) is doubtful since this has been associated with failure by some authors. ${ }^{10-12,42,43}$ The incidence of subsidence of the Exeter femoral component greater than $5 \mathrm{~mm}$ after impaction grafting reported in the literature has varied between $13 \%$ and $33 \% .^{7-9,34,44}$ In these studies subsidence of more than $10 \mathrm{~mm}$ was not considered to be a failure of cemented fixation since it was not detrimental to the clinical outcome. ${ }^{7,8}$ For our study we used a standard Charnley-Kerboull femoral component for which long-term clinical and radiological results have been reported. ${ }^{45-49}$ The mechanical behaviour of this component in impaction grafting was similar to that seen after primary THR, provided that the cement-graft interface was stable. Some authors have reported the results of impaction grafting using the Charnley Elite plus (DePuy, Leeds, United Kingdom) or other composite beam femoral components. ${ }^{36,37,39,50-53}$ Their results were good, indicating a lower rate of early subsidence, but Ullmark et $\mathrm{al}^{53}$ reported a higher rate of aseptic loosening.

No femoral fractures were observed in our study, although only femoral components of standard length were used. Several factors may explain this important difference when compared with earlier studies which quote rates of fracture ranging from $4 \%{ }^{7}$ to $11 \%{ }^{24}$ The lack of subsidence of the component protected the distal part of the reconstruction from overstress. This feature was crucial in hips with distal cortical weakness or reconstruction. The primary stability of the femoral component allowed good healing of the graft in these critical areas since the distal femur developed sufficient mechanical resistance to support it. Moreover, all hips with distal defects or cortical weakness had been reconstructed by allograft cortical struts and intramedullary grafting. Despite the experimental work reported by Bolder et al, ${ }^{54}$ our results suggest that this is a better way of achieving biological healing and thickening of deficient areas than by reconstructions supported by a metal mesh or plate. A more recent in vitro study has shown that extramedullary reinforcement with a strut reduces the strain at the defect by $50 \%$ when compared with a similar reconstruction performed with a mesh. ${ }^{55}$ The use of long femoral stems has been advocated in order to decrease the rate of fracture after impaction grafting. Sierra et $\mathrm{al}^{56}$ described a series of 42 hips which had undergone femoral impaction grafting with stems 220 $\mathrm{mm}$ or more in length. At a mean follow-up of 7.5 years, four fractures occurred, an incidence of $4.8 \%$. They concluded that all areas of lysis or cortical thinning should be treated aggressively at the time of surgery. In our view, the use of long femoral components should be restricted to hips with major loss of bone at the distal femur, to patients unable to sustain partial weight-bearing during the postoperative period, and in hips with a varus curvature of the femur. Since we have respected these indications, and used other techniques like bone reconstruction with a massive allograft and a long cemented femoral component in such cases, we have not observed any fractures in our study.

Our study confirms the ability of impaction grafting, in combination with a cemented femoral component, to achieve a stable and durable bony reconstruction in severe femoral bone loss. The use of a double-tapered and highlypolished Charnley-Kerboull femoral component was associated with a low rate of subsidence and reconstruction of distal bone deficiencies with struts of cortical allograft appeared to be an efficient method of preventing post-operative fracture for up to 16 years, despite the use of a standard component.

No benefits in any form have been received or will be received from a commercial party related directly or indirectly to the subject of this article.

\section{References}

1. Stromberg CN, Herberts P, Palmertz B. Cemented revision hip arthroplasty: a multicenter 5-9-year study of 204 first revisions for loosening. Acta Orthop Scand 1992;63:111-19.

2. Engh CA Jr, Ellis TJ, Koralewicz LM, McAuley JP, Engh CA Sr. Extensively porous-coated femoral revision for sever femoral bone loss: minimum 10-year followup. J Arthroplasty 2002;17:955-60.

3. Gutierrez Del Alamo J, Garcia-Cimbrelo E, Castellanos V, Gil-Garay E. Radiographic bone regeneration and clinical outcome with the Wagner SL revision stem: a 5-year to 12-year follow-up study. J Arthroplasty 2007;22:515-24.

4. Blackley HR, Davis AM, Hutchison CR, Gross AE. Proximal femoral allografts for reconstruction of bone stock in revision arthroplasty of the hip: a nine to fifteen-year follow-up. J Bone Joint Surg [Am] 2001;83-A:346-54.

5. Simon JP, Fowler JL, Gie GA, Ling RS, Timperley AJ. Impaction cancellous grafting of the femur in cemented total hip arthroplasty. J Bone Joint Surg [Br] 1991;73B(Suppl 1).

6. Gie GA, Linder $\mathbf{L}$, Ling RS, et al. Impacted cancellous allografts and cement for revision total hip arthroplasty. J Bone Joint Surg [Br] 1993;75-B:14-21.

7. Halliday BR, English HW, Timperley AJ, Gie GA, Ling RS. Femoral impaction grafting with cement in revision total hip replacement: evolution of the technique and results. J Bone Joint Surg [Br] 2003;85-B:809-17.

8. Schreurs BW, Arts JJ, Verdonschot $\mathbf{N}$, et al. Femoral component revision with use of impaction bone-grafting and a cemented polished stem. J Bone Joint Surg [Am] 2005;87-A:2499-507. 
9. Wraighte PJ, Howard PW. Femoral impaction bone allografting with an Exeter cemented collarless, polished, tapered stem in revision hip replacements: a mean follow-up of 10.5 years. J Bone Joint Surg [Br] 2008;90-B:1000-4.

10. Eldridge JD, Smith E, Hubble MJ, Whitehouse SL, Learmonth ID. Massive early subsidence following femoral impaction grafting. J Arthroplasty 1997;12:535-40.

11. Jazrawi LM, Della Valle CJ, Kummer FJ, Adler EM, Di Cesare PE. Catastrophic failure of a cemented, collarless, polished, tapered cobalt-chromium femoral stem used with impaction bone-grafting: a report of two cases. J Bone Joint Surg [Am] 1999;81-A:844-7.

12. Pekkarinen J, Alho A, Lepisto J, et al. Impaction bone grafting in revision hip surgery: a high incidence of complications. J Bone Joint Surg [Br] 2000;82-B:103-7.

13. Ornstein E, Atroshi I, Franzen $\mathbf{H}$, et al. Early complications after one hundred and forty-four consecutive hip revisions with impacted morselized allograft bone and cement. J Bone Joint Surg [Am] 2002;84-A:1323-8.

14. Hassaballa M, Mehendale S, Poniatowski S, et al. Subsidence of the stem after impaction bone grafting for revision hip replacement using irradiated bone. J Bone Joint Surg [Br] 2009;91-B:37-43.

15. Steinbrink K. Procedure in extensive or complete loss of bone substance of the femur following shaft loosening. Orthopade 1987;16:277-86 (in German)

16. Kerboull M, Kerboull L. Traitement chirurgical des descellements femoraux aseptiques. Orthopedie-Traumatologne 2000;10:44-676.

17. Merle d'Aubigné R. Numerical evaluation of hip function. Rev Chir Orthop Réparatrice Appar Mot 1970;56:481-6 (in French).

18. Gruen TA, McNeice GM, Amstutz HC. "Modes of failure" of cemented stem-type femoral components: a radiographic analysis of loosening. Clin Orthop 1979;141:17

19. Fowler JL, Gie GA, Lee AJ, Ling RS. Experience with the Exeter total hip replacement since 1970. Orthop Clin North Am 1988;19:477-89.

20. Brooker AF, Bowerman JW, Robinson RA, Riley LJ. Ectopic ossification follow ing total hip replacement: incidence and a method of classification. J Bone Joint Surg [Am] 1973;55-A:1629-32.

21. Harris WH, McGann WA. Loosening of the femoral component after use of the medullary-plug cementing technique: follow-up note with a minimum five-year follow-up. J Bone Joint Surg [Am] 1986;68-A:1064-6.

22. Mantel N, Haenzel W. Statistical aspects of the analysis of data from retrospective studies of disease. J Nat Cancer Inst 1959;22:719-48.

23. Murray DW, Carr AJ, Bulstrode C. Survival analysis of joint replacements. J Bone Joint Surg [Br] 1993;75-B:697-704.

24. Cabanela ME, Trousdale RT, Berry DJ. Impacted cancellous graft plus cement in hip revision. Clin Orthop 2003;417:175-82.

25. Elting JJ, Mikhail WE, Zicat BA, et al. Preliminary report of impaction grafting for exchange femoral arthroplasty. Clin Orthop 1995;319:159-67.

26. Fetzer GB, Callaghan JJ, Templeton JE, et al. Impaction allografting with cement for extensive femoral bone loss in revision hip surgery: a 4- to 8-year follow-up study. J Arthroplasty 2001;16(Suppl 1):195-202.

27. Linder L. Cancellous impaction grafting in the human femur: histological and radiographic observations in 6 autopsy femurs and 8 biopsies. Acta Orthop Scand 2000;71:543-52.

28. Brewster NT, Gillespie WJ, Howie CR, et al. Mechanical considerations in impaction bone grafting. J Bone Joint Surg [Br] 1999;81-B:118-24

29. Giesen EB, Lamerigts NM, Verdonschot $\mathbf{N}$, et al. Mechanical characteristics of impacted morsellised bone grafts used in revision of total hip arthroplasty. J Bone Joint Surg [Br] 1999;81-B:1052-7.

30. Hostner J, Hultmark P, Karrholm J, Malchau H, Tveit M. Impaction technique and graft treatment in revisions of the femoral component: laboratory studies and clinical validation. J Arthroplasty 2001;16:76-82.

31. Malkani AL, Voor MJ, Fee KA, Bates CS. Femoral component revision using impacted morsellised cancellous graft: a biomechanical study of implant stability. Bone Joint Surg [Br] 1996;78-B:973-8.

32. de Roeck N, Drabu KJ. Impaction bone grafting using freeze-dried allograft in revision hip arthroplasty. J Arthroplasty 2001;16:201-6.

33. Dunlop DG, Brewster NT, Madabhushi SP, et al. Techniques to improve the shea strength of impacted bone graft: the effect of particle size and washing of the graft. J Bone Joint Surg [Am] 2003;85-A:639-46.

34. Kligman M, Con V, Roffman M. Cortical and cancellous morselized allograft in revision total hip replacement. Clin Orthop 2002;401:139-48.
35. Williams HD, Browne G, Gie GA, et al. The Exeter universal cemented femoral component at 8 to 12 years: a study of the first 325 hips. J Bone Joint Surg [Br] 2002;84-B:324-34

36. Alfaro-Adrian J, Gill HS, Murray DW. Cement migration after THR: a comparison of charnley elite and exeter femoral stems using RSA. J Bone Joint Surg [Br] 1999;81B:130-4.

37. Karrholm J, Hultmark P, Carlsson L, Malchau H. Subsidence of a non-polished stem in revisions of the hip using impaction allograft: evaluation with radiostereometry and dual-energy X-ray absorptiometry. J Bone Joint Surg [Br] 1999;81-B:135-42.

38. Ornstein $\mathbf{E}$, Franzen $\mathbf{H}$, Johnsson $\mathbf{R}$, et al. Hip revision using the Exeter stem, impacted morselized allograft bone and cement: a consecutive 5-year radiostereometric and radiographic study in 15 hips. Acta Orthop Scand 2004;75:533-43.

39. van Doorn WJ, ten Havel BL, van Biezen FC, et al. Migration of the femoral stem after impaction bone grafting: first results of an ongoing, randomised study of the exeter and elite plus femoral stems using radiostereometric analysis. J Bone Joint Surg $[B r] 2002 ; 84-B: 825-31$

40. Young L, Duckett S, Dunn A. The use of the cemented Exeter Universal femoral stem in a District General Hospital: a minimum ten-year follow-up. J Bone Joint Surg [Br] 2009:91-B:170-5.

41. de Kam DC, Klarenbeek RL, Gardeniers JW, Veth RP, Schreurs BW. The medium-term results of the cemented Exter femoral component in patients under 40 years of age J Bone Joint Surg [Br]2008;90-B:1417-21.

42. Masterson EL, Masri BA, Duncan CP, et al. The cement mantle in femoral impaction allografting: a comparison of three systems from four centres. J Bone Joint Surg [Br] 1997;79-B:908-13.

43. Meding JB, Ritter MA, Keating EM, Faris PM. Impaction bone-grafting before insertion of a femoral stem with cement in revision total hip arthroplasty: a minimum two-year follow-up study. J Bone Joint Surg [Am] 1997;79-A:1834-41.

44. Mikhail WE, Wretenberg PF, Weidenhielm LR, Mikhail N, Bauer T. Complex cemented revision using polished stem and morselised allograft: minimum 5-years' follow-up. Arch Orthop Trauma Surg 1999;119:288-91.

45. Hamadouche M, El Masri F, Lefevre N, Courpied JP, Kerboul M. Long-term migration using EBRA-FCA of stems cemented line-to-line according to the "French Paradox" principles [abstract]. 54th Annual Meeting Orthopaedic Research Society 2008.

46. Hamadouche M, Kerboull L, Meunier A, Courpied J, Kerboull M. Total hip arthroplasty for the treatment of ankylosed hips: a five to twenty-one-year follow-up study. J Bone Joint Surg [Am] 2001;83-A:992-8.

47. Kerboull M, Hamadouche M, Kerboull L. Total hip arthroplasty for Crowe type IV developmental hip dysplasia: a long-term follow-up study. J Arthroplasty 2001;16(Suppl 1):170-6

48. Kerboull L, Hamadouche M, Courpied JP, Kerboull M. Long-term results of Charnley-Kerboull hip arthroplasty in patients younger than 50 years. Clin Orthop 2004:418:112-18.

49. Nich C, Courpied JP, Kerboull M, Postel M, Hamadouche M. Charnley-Kerboull total hip arthroplasty for osteonecrosis of the femoral head: a minimum 10-year follow-up study. J Arthroplasty 2006;21:533-40.

50. Boldt JG, Dilawari P, Agarwal S, Drabu KJ. Revision total hip arthroplasty using impaction bone grafting with cemented nonpolished stems and charnley cups. J Arthroplasty 2001;16:943-52.

51. Piccaluga F, Gonzalez Della Valle A, Encinas Fernandez JC, Pusso R. Revision for the femoral prosthesis with impaction allografting and a Charnley stem: a 2- to 12year follow-up. J Bone Joint Surg [Br] 2002;84-B:544-9.

52. Leopold SS, Berger RA, Rosenberg AG, et al. Impaction allografting with cement for revision of the femoral component: a minimum four-year follow-up study with use of a precoated femoral stem. J Bone Joint Surg [Am] 1999;81-A:1080-92.

53. Ullmark G, Hallin G, Nilsson 0. Impacted corticocancellous allografts and cement for femoral revision of total hip arthroplasty using Lubinus and Charnley prostheses. J Arthroplasty 2002:17:325-34.

54. Bolder SB, Schreurs BW, Verdonschot N, Veth RP, Buma P. Wire mesh allows more revascularization than a strut in impaction bone grafting: an animal study in goats. Clin Orthop 2004:423:280-6.

55. Barker R, Takahashi T, Toms A, Gregson P, Kuiper JH. Reconstruction of femoral defects in revision hip surgery: risk of fracture and stem migration after impaction grafting. J Bone Joint Surg [Br] 2006;88-B:832-6.

56. Sierra RJ, Charity J, Tsiridis E, Timperley J, Gie GA. The use of long cemented stems for femoral impaction grafting in revision total hip arthroplasty. J Bone Joint Surg $[A m] 2008 ; 90-A: 1330-6$. 